\title{
Comparison of clinical features and outcomes in COVID-19 and influenza pneumonia patients requiring intensive care unit admission
}

\author{
A. Oliva ${ }^{1}$ (1) - G. Ceccarelli ${ }^{1} \cdot$ C. Borrazzo ${ }^{1} \cdot$ M. Ridolfi ${ }^{1} \cdot$ G. D. Ettorre $^{1} \cdot$ F. Alessandri ${ }^{2} \cdot$ F. Ruberto $^{2} \cdot$ F. Pugliese $^{2}$. \\ G. M. Raponi ${ }^{1}$ - A. Russo ${ }^{1}$ - A. Falletta ${ }^{1}$. C. M. Mastroianni ${ }^{1} \cdot$ M. Venditti $^{1}$
}

Received: 26 April 2021 / Accepted: 3 May 2021 / Published online: 26 May 2021

(c) The Author(s) 2021

\begin{abstract}
Background Little is known in distinguishing clinical features and outcomes between coronavirus disease-19 (COVID-19) and influenza (FLU).

Materials/methods Retrospective, single-centre study including patients with COVID-19 or FLU pneumonia admitted to the Intensive care Unit (ICU) of Policlinico Umberto I (Rome). Aims were: (1) to assess clinical features and differences of patients with COVID-19 and FLU, (2) to identify clinical and/or laboratory factors associated with FLU or COVID-19 and (3) to evaluate 30-day mortality, bacterial superinfections, thrombotic events and invasive pulmonary aspergillosis (IPA) in patients with FLU versus COVID-19.

Results Overall, 74 patients were included (19, 25.7\%, FLU and 55, 74.3\%, COVID-19), median age 67 years (58-76). COVID-19 patients were more male ( $p=0.013$ ), with a lower percentage of COPD (Chronic Obstructive Pulmonary Disease) and chronic kidney disease (CKD) ( $p=0.001$ and $p=0.037$, respectively) than FLU. SOFA score was higher $(p=0.020)$ and lymphocytes were significantly lower in FLU than in COVID-19 [395.5 vs 770.0 cells $/ \mathrm{mmc}, p=0.005$ ]. At multivariable analysis, male sex (OR 6.1, $<<0.002)$, age $>65$ years (OR 2.4, $p=0.024)$ and lymphocyte count $>725$ cells $/ \mathrm{mmc}$ at ICU admission (OR 5.1, $\mathrm{p}=0.024)$ were significantly associated with COVID-19, whereas CKD and COPD were associated with FLU (OR 0.1 and OR $0.16, p=0.020$ and $p<0.001$, respectively). No differences in mortality, bacterial superinfections and thrombotic events were observed, whereas IPA was mostly associated with FLU (31.5\% vs 3.6\%, $p=0.0029)$.

Conclusions In critically ill patients, male sex, age $>65$ years and lymphocytes $>725$ cells/mmc are related to COVID-19. FLU is associated with a significantly higher risk of IPA than COVID-19.
\end{abstract}

Keywords COVID-19 - Influenza · SARS-CoV-2 - Intensive care unit · Invasive pulmonary aspergillosis · Superinfections · Thrombotic events

A Oliva and G Ceccarelli have authors contributed equally to this paper

A. Oliva

alessandra.oliva@uniroma1.it

1 Department of Public Health and Infectious Diseases, Sapienza University of Rome, Piazzale Aldo Moro 5, 00185 Rome, Italy

2 Department of Anesthesia and Critical Care Medicine, Sapienza University of Rome, Policlinico Umberto I, Rome, Italy

\section{Introduction}

The novel $\beta$-coronavirus, named Severe Acute Respiratory Syndrome Coronavirus 2 (SARS-CoV-2), due to the similarity with the virus that caused the SARS outbreak in 2002-2004, emerged in Wuhan, China, in December 2019 and has rapidly spread through the world causing the ongoing pandemic [1]. At the time of writing, it has infected over 112 million people and resulted in more than 2.4 million deaths worldwide, especially in patients admitted to Intensive Care Unit (ICU) or those developing Acute Respiratory Distress Syndrome (ARDS) [2]. 
As a consequence, the adopted interventions such as lockdown and social limitation contributed also to the reduction of other respiratory viral infections including influenza [3].

SARS-CoV-2 and influenza viruses share similar aspects, from their ease of transmission from person-to-person through the respiratory droplet route to their clinical presentation. In fact, both viruses can cause acute respiratory failure that might require hospitalization in ICU, might be complicated by bacterial and fungal superinfections and might predispose subjects to the development of thrombosis [4-11].

However, little is known in distinguishing clinical features and outcomes in critically ill patients with coronavirus disease-19 (COVID-19) and influenza (FLU) requiring ICU admission.

The development of bacterial and fungal superinfections occurs likely due to severe pulmonary inflammation, compromised pulmonary defenses, ventilator dependence, and the receipt of immunosuppressive drugs, all conditions present during FLU and COVID-19 [4, 5, 12]. In particular, while the development of influenza-associated pulmonary aspergillosis (IAPA) is a well-recognized condition, the occurrence of invasive pulmonary aspergillosis (IPA) as a consequence of COVID-19, although increasingly reported, is still a matter of debate [13-16]. Several reports of COVID-19-associated pulmonary aspergillosis (CAPA) have been described so far; however, the real incidence of this condition in critically ill patients is still unknown, ranging from 3.3 to $33.3 \%$, and comprehensive data are lacking [17-27].

Pulmonary thrombosis and vasculitis occur in subgroups of adult patients with severe influenza, but this phenomenon seemed to be highly prevalent in patients with COVID-19 and has been considered also responsible for unfavorable outcomes $[9,28]$.

Therefore, based on these premises, the aims of the study were: (1) to assess the clinical features and differences of critically ill patients with COVID-19 and FLU, (2) to identify clinical and/or laboratory factors associated with FLU or COVID-19 and (3) to evaluate the clinical outcomes in critically ill patients with FLU and COVID-19, expressed as 30-day mortality, development of bacterial superinfections, documented thrombotic events and IPA.

\section{Materials and method}

\section{Study population}

A retrospective, single-center study including all adult patients with diagnosis of COVID-19 or severe FLU requiring ICU admission and hospitalized at Azienda Policlinico Umberto I, "Sapienza" University of Rome was performed.
Patients with FLU and COVID-19 pneumonia were hospitalized from January to December 2019 and from March to September 2020, respectively. During the 2020 winter season, our hospital was exclusively dedicated to the cure of COVID-19 patients; therefore, no patients with FLU in 2020 could have been included in the study.

Nasopharyngeal swab samples or bronchoalveolar fluid were collected and SARS-CoV-2 or influenza RNA were detected using RT-PCR (RealStar SARS-CoV2 RT-PCR, Altona Diagnostics). For each subject, demographic, laboratory, clinical and radiological data were collected and recorded anonymously in an electronic database. The study was approved by the local Ethics Committee (ID Prot. 109/2020).

As for local protocol, screening for multi-drug-resistant bacteria (i.e., methicillin-resistant Staphylococcus aureus, MRSA, or carbapenem resistant Gram-negative bacilli) colonization was systematically performed by means of rectal swab and lower respiratory tract cultures. The clinical approach to bacterial and fungal superinfection was managed by two dedicated ID physicians (GC and MV).

In 18 out of 19 FLU and all COVID-19 patients, BAL with fungal cultures was systematically performed at ICU admission and every 7 days. In FLU patients, BAL GM was performed either at ICU admission or subsequently based on clinical suspicion of IPA superinfection: thus, it was eventually done in 5 patients (Fig. 1). On the other hand, in the COVID-19 cohort, BAL GM was performed in 39 out of 55 patients (70.9\%). As shown in Fig. 1, during the first period of the study (March-May 2020), BAL for GM was collected only on ICU admission in 22 out of 39 COVID-19 patients $(56.4 \%)$. Based on the increasing numbers of CAPA reports accumulating in the literature [17-27], in the second period of the study (June 2020-September 2020), BAL for GM was collected also at day 7 ( \pm 2 days) and in instances of pulmonary disease progression.

Fungal cultures were incubated for 7 days at $30{ }^{\circ} \mathrm{C}$ on Sabouraud selective media. GM test in serum and BAL was performed according to manufacturer's instructions (Platelia Aspergillus EIA, Bio-Rad).

Clinical outcomes included 30-day mortality, bacterial superinfections, thrombotic/embolic events and the development of IPA.

\section{Definitions}

As for COVID-19, definition of pneumonia or severe pneumonia was based on the WHO interim guidance and included clinical signs of pneumonia (fever, cough, dyspnea, fast breathing) with or without signs of severe pneumonia such as respiratory rate $>30$ breaths/min, severe respiratory distress, or $\mathrm{SpO} 2<90 \%$ on room air [29]. 

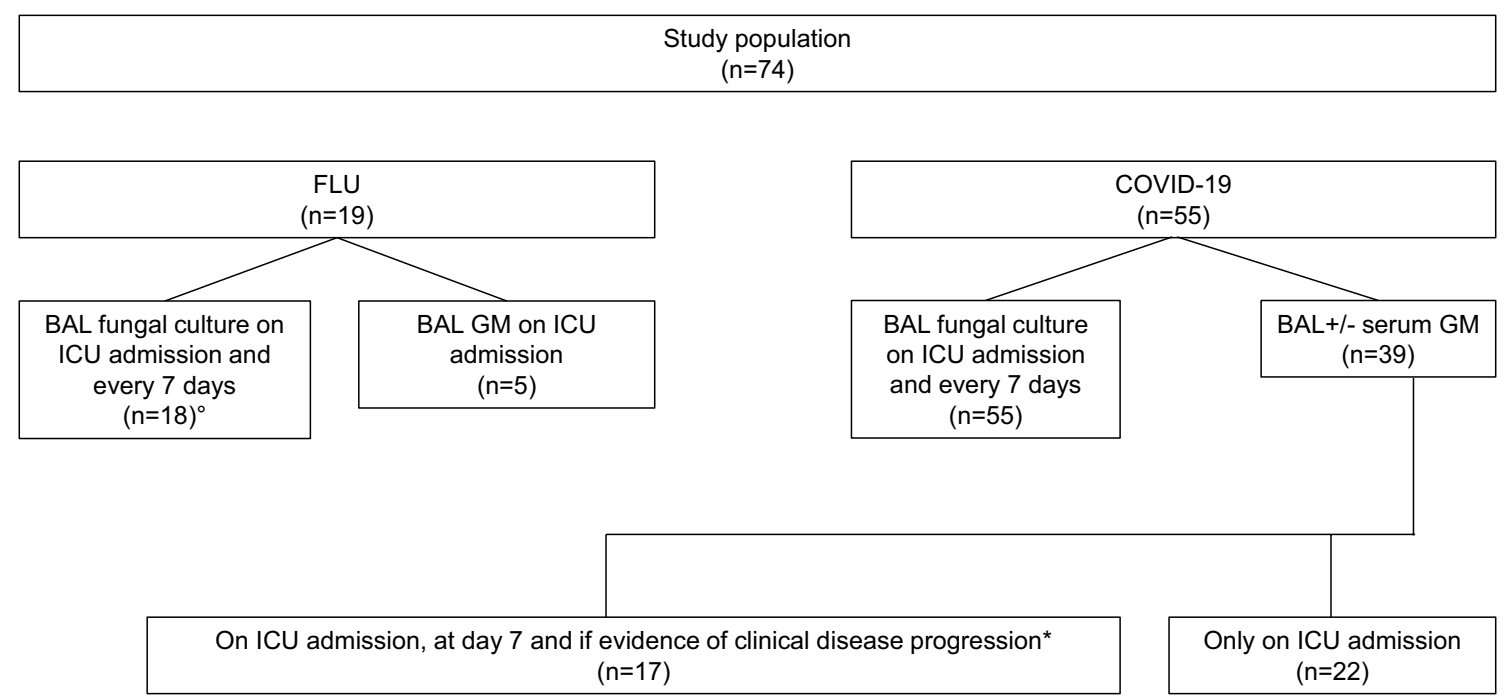

Fig. 1 Flowchart of the study. FLU influenza, COVID-19 Coronavirus Disease 19, BAL Bronchoalveolar lavage, GM galactomannan, ICU Intensive Care Unit. a according to the algorithm proposed by Bar-

Thrombotic/embolic events were defined as the appearance of new ischemic/embolic events diagnosed as follows: (1) pulmonary thrombo-embolism by lung computed tomography (CT) scan (2) myocardial infarction by EKG changes associated with enhanced markers of cell necrosis (3) acute brain ischemia by onset of new focal neurological signs and symptoms and confirmed, whenever possible, by magnetic resonance or CT imaging and (4) acute limb ischemia [5].

Bacterial superinfections were diagnosed and defined in accordance to guidelines [4].

IPA following FLU (IAPA) was defined in accordance with the recent expert case definition and modified AspICU algorithm [13, 14]. IPA following COVID-19 was defined according to the modified AspICU algorithm [13] and/or the recently proposed definition of CAPA: COVID-19 positive ICU patients with pulmonary infiltrates (entry criterion) who had at least one of the following (a) serum galattomannan (GM) index $>0.5$ or (b) bronchoalveolar (BAL) GM index $>1.0$ or (c) positive Aspergillus spp BAL culture or (d) cavitating infiltrate (not attributed to another cause) in the area of the pulmonary infiltrate [16].

\section{Statistical analysis}

All statistical data were analyzed using the Statistical Package for the Social Sciences (SPSS) version 22. The data, unless otherwise stated, were given as means with standard deviation (SD), minimum and maximum or medians with Interquartile ranges (IQR, 25th-75th) for continuous variables and as simple frequencies, proportions and relative percentages for dichotomous variables. Student's $t$ test or Mann-Whitney U test were used for comparison means or toletti et al. [17]. b in case\#6 BAL was not performed and invasive pulmonary aspergillosis (IPA) was proven at autopsy

medians in the univariate analyses. Between-group comparisons of dichotomous variables were conducted by using chi-square tests (or Fisher's exact test) and odds ratios (ORs) with $95 \%$ confidence intervals (95\% CIs). OR values $<1$ indicates association with FLU, whereas ORs $>1$ indicates association with COVID-19. For lymphocytes, an absolute count of 725 cells $/ \mathrm{mmc}$ was used [30]. $p$ value analyses were two-sided and a $p$ value of less than 0.05 was considered statistically significant.

\section{Results}

\section{Study population}

Overall, 74 critically ill patients were included in the study (19, 25.7\%, with FLU and 55, 74.3\%, with COVID-19, respectively), median age was 67 years (58-76) (71.5 vs 67 for FLU and COVID-19 subjects, respectively, $p=0.807$ ) (Table 1). All but one in the FLU group were communityacquired infections. Compared with FLU ones, patients with COVID-19 were more frequently male $(44,80 \%, v s 9,47 \%$, $p=0.013)$. Overall, no differences in the Charlson Comorbidity Index were found between the 2 groups $(p=0.102)$, with a lower percentage of smoke, COPD (Chronic Obstructive Pulmonary Disease) and chronic kidney disease (CKD) in patients with COVID-19 than those with FLU (25\% vs $63.1 \%, p=0.004,20 \%$ vs $57.8 \%, p=0.003$ and $4 \%$ vs $26.3 \%, p=0.010$, respectively). At ICU admission, severity of infection was higher in FLU than in COVID-19 patients (median SOFA score 6 vs 4, $p=0.020$ ) (Fig. 2a). White Blood Cells (WBCs) were higher in FLU than in COVID-19 
Table 1 General characteristics of study population

\begin{tabular}{|c|c|c|c|c|}
\hline Parameter & $\begin{array}{l}\text { Total } \\
N=74\end{array}$ & $\begin{array}{l}\text { FLU } \\
N=19\end{array}$ & $\begin{array}{l}\text { COVID }-19 \\
N=55\end{array}$ & $p$ value \\
\hline Male Sex, $n(\%)$ & $52(71)$ & $9(47)$ & $44(80)$ & 0.013 \\
\hline Age, y, median (IQR) & $67(58-76)$ & $71.5(59.5-76.75)$ & $67(58-75)$ & 0.807 \\
\hline $\begin{array}{l}\text { WBC, cells/ } \mu \mathrm{L} \\
\text { median (IQR) }\end{array}$ & $\begin{array}{l}8550 \\
\quad(5260-11600)\end{array}$ & $\begin{array}{l}12010 \\
\quad(9820-12700)\end{array}$ & $\begin{array}{l}7030 \\
\quad(4927-9510)\end{array}$ & 0.015 \\
\hline $\begin{array}{l}\text { Neutrophils, cells/ } \mu \mathrm{L} \\
\text { median (IQR) }\end{array}$ & $\begin{array}{l}7094 \\
\quad(4070-10158)\end{array}$ & $\begin{array}{l}10665 \\
\qquad(9345-11812)\end{array}$ & $\begin{array}{l}5705 \\
\quad(3677-8332)\end{array}$ & 0.001 \\
\hline $\begin{array}{l}\text { Lymphocytes, cells/ } \mu \mathrm{L} \\
\text { median (IQR) }\end{array}$ & $610(370-1036)$ & $395.5(316-541)$ & $770(465-1165)$ & 0.005 \\
\hline $\begin{array}{l}\mathrm{CRP}, \mathrm{mg} / \mathrm{dL} \\
\text { median (IQR) }\end{array}$ & $\begin{array}{l}12.67 \\
(5.37-28.47)\end{array}$ & $\begin{array}{l}50.9 \\
\quad(22.6-54.2)\end{array}$ & $\begin{array}{l}12 \\
(5.03-25.45)\end{array}$ & 0.113 \\
\hline Smoke, $n(\%)$ & $26(35.1)$ & $12(63.15)$ & $14(25)$ & 0.004 \\
\hline CCI, median (IQR) & $3(2-5)$ & $4(2-7)$ & $3(1.5-4.5)$ & 0.102 \\
\hline SOFA, median (IQR) & $4(3-5)$ & $6(3-8)$ & $4(2.75-5)$ & 0.02 \\
\hline$\geq 1$ comorbidity, $n(\%)$ & $56(75.6)$ & $16(84)$ & $40(73)$ & 0.37 \\
\hline COPD, $n(\%)$ & $22(29.7)$ & $11(57.8)$ & $11(20)$ & 0.003 \\
\hline $\mathrm{CKD}, n(\%)$ & $7(9.4)$ & $5(26.3)$ & $2(4)$ & 0.01 \\
\hline Hemodialysis, $n(\%)$ & $23(31)$ & $4(21)$ & $19(35)$ & 0.39 \\
\hline ECMO, $n(\%)$ & $8(10.8)$ & $3(15.7)$ & $5(9)$ & 0.415 \\
\hline Hypertension, $n(\%)$ & $36(48.6)$ & $7(36.8)$ & $29(53)$ & 0.29 \\
\hline $\mathrm{CAD}, n(\%)$ & $21(28.3)$ & $7(36.8)$ & $14(25)$ & 0.38 \\
\hline Cirrhosis, $n(\%)$ & $0(0)$ & $0(0)$ & $0(0)$ & - \\
\hline Diabetes mellitus, $n(\%)$ & $22(29.7)$ & $7(36.8)$ & $15(27)$ & 0.56 \\
\hline Neurological disorders, $n(\%)$ & $3(4)$ & $1(5.2)$ & $2(4)$ & 0.9 \\
\hline Cancer, $n(\%)$ & $5(6.7)$ & $1(5.2)$ & $4(7)$ & 0.9 \\
\hline Corticosteroids, $n(\%)$ & $18(24.3)$ & $5(26.3)$ & $13(24)$ & 0.9 \\
\hline Dosage of methylprednisolone, $\mathrm{mg} / \mathrm{kg} / \mathrm{die}$, median (IQR) & $0(0-0.4)$ & $0.4(0-1)$ & $0(0-0)$ & 0.01 \\
\hline Use of broad spectrum antibiotics, $n(\%)$ & $64(86.4)$ & $12(63.1)$ & $51(92.7)$ & 0.0048 \\
\hline Length of hospitalization, days, median (IQR) & $22(15.5-38.5)$ & $21(12-37)$ & $23(17.5-36.5)$ & 0.678 \\
\hline Pulmonary super-infections, $n(\%)$ & $31(73.8)$ & $11(57.8)$ & $20(36)$ & 0.11 \\
\hline MRSA & $2(6.4)$ & $0(0)$ & $2(10)$ & 0.52 \\
\hline KPC & $1(3.3)$ & $0(0)$ & $1(5)$ & 0.9 \\
\hline OXA-48 & $3(9.6)$ & $0(0)$ & $3(15)$ & 0.53 \\
\hline Acinetobacter baumanii & $9(29.1)$ & $4(36.4)$ & $5(25)$ & 0.68 \\
\hline Pseudomonas aeruginosa & $10(32.3)$ & $2(18.2)$ & $8(40)$ & 0.26 \\
\hline Others* & $6(19.3)$ & $5(45.4)$ & $1(5)$ & 0.01 \\
\hline BSI, $n(\%)$ & $31(41.8)$ & $8(42.1)$ & $23(42)$ & 0.589 \\
\hline Microorganisms of $\mathrm{BSI}^{\circ}, n(\%)$ & $38(100)$ & $10(26.3)$ & $28(73.7)$ & \\
\hline MRSA & $1(2.6)$ & $0(0)$ & $1(3.5)$ & - \\
\hline KPC & $6(15.7)$ & $3(30)$ & $3(10.7)$ & 0.31 \\
\hline OXA-48 & $1(2.6)$ & $0(0)$ & $1(3.5)$ & - \\
\hline Acinetobacter baumanii & $5(13.1)$ & $0(0)$ & $5(17.8)$ & 0.29 \\
\hline Pseudomonas aeruginosa & $1(2.6)$ & $1(10)$ & $0(0)$ & - \\
\hline Candida spp & $4(10.5)$ & $1(10)$ & $3(10.7)$ & 0.9 \\
\hline CoNS & $13(34.2)$ & $3(30)$ & $10(35.7)$ & 0.9 \\
\hline Enterococcus spp & $3(7.8)$ & $1(10)$ & $2(7.1)$ & 0.9 \\
\hline Enterobacterales & $4(10.5)$ & $1(10)$ & $3(10.7)$ & 0.9 \\
\hline \multicolumn{5}{|l|}{ NO KPC NO OXA-48 } \\
\hline MDR colonization, $n(\%)$ & $20(27)$ & $7(36.8)$ & $13(24)$ & 0.564 \\
\hline KPC & $7(9.4)$ & $4(21)$ & $3(5)$ & 0.06 \\
\hline
\end{tabular}


Table 1 (continued)

\begin{tabular}{|c|c|c|c|c|}
\hline Parameter & $\begin{array}{l}\text { Total } \\
N=74\end{array}$ & $\begin{array}{l}\text { FLU } \\
N=19\end{array}$ & $\begin{array}{l}\text { COVID-19 } \\
N=55\end{array}$ & $p$ value \\
\hline OXA-48 & $4(5.4)$ & $0(0)$ & $4(7)$ & 0.252 \\
\hline Acinetobacter baumanii & $9(12.1)$ & $1(5.1)$ & $8(15)$ & 0.42 \\
\hline Pulmonary aspergillosis, $n(\%)$ & $8(10.8)$ & $6(31.5)$ & $2(3.6)$ & 0.0029 \\
\hline Thrombotic events, $n(\%)$ & $15(20)$ & $3(15.7)$ & $12(21.8)$ & 0.521 \\
\hline 30-day mortality, $n(\%)$ & $50(67.5)$ & $12(63.2)$ & $38(69)$ & 0.77 \\
\hline
\end{tabular}

COVID-19 coronavirus disease-19; FLU influenza; IQR interquartile range; WBC white blood cells; CRP C-reactive protein; $C C I$ charlson comorbidity index; SOFA sequential organ failure assessment; $C O P D$ chronic obstructive pulmonary disease; u1xygenation; $C A D$ coronary artery disease; MRSA methicillin-resistant Staphylococcus aureus; KPC Klebsiella pneumoniae carbapenemase; BSI bloodstream infection; CoNS coagulase negative Staphylococci; $M D R$ multi-drug resistance.

${ }^{a}$ Others include: Streptococcus pneumoniae $(n=1)$, Stenotrophomonas maltophilia $(n=2)$, Enterobacterales other than KPC and OXA-48 $(n=3)$

${ }^{\mathrm{b}}$ Number of microorganisms causing BSI is higher than the number of patients with BSI

A

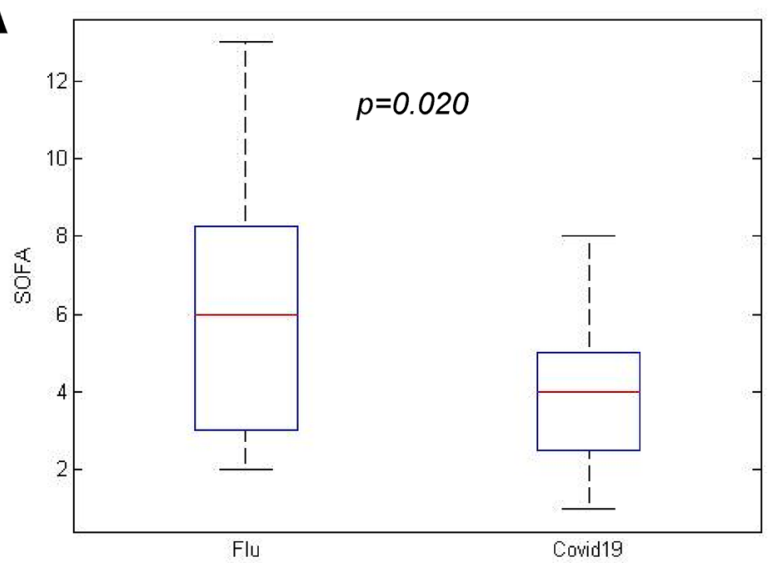

C

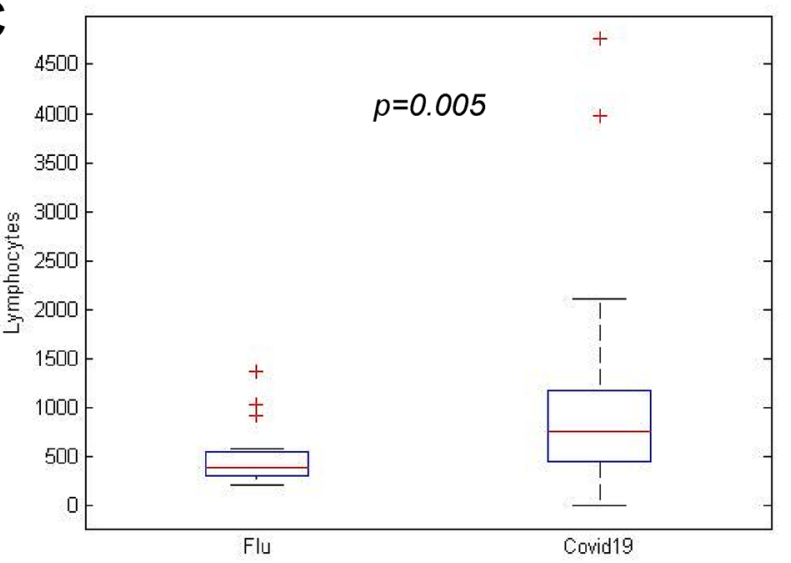

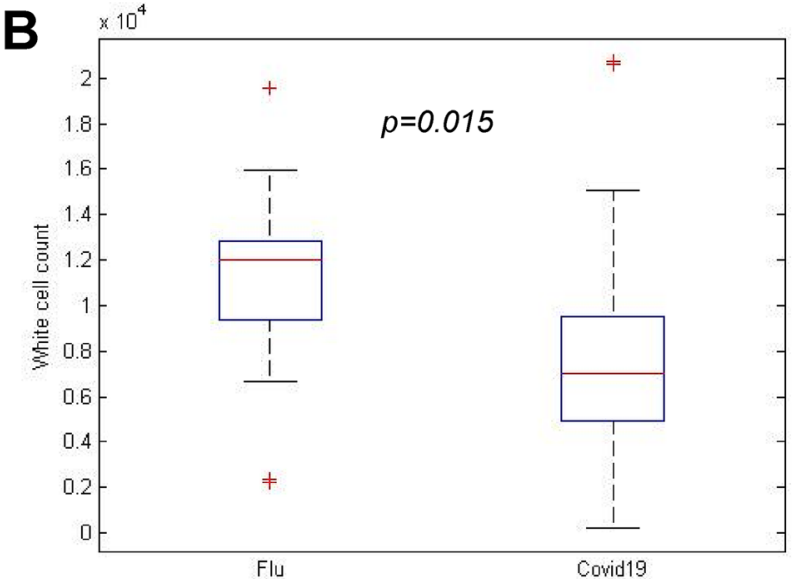

D

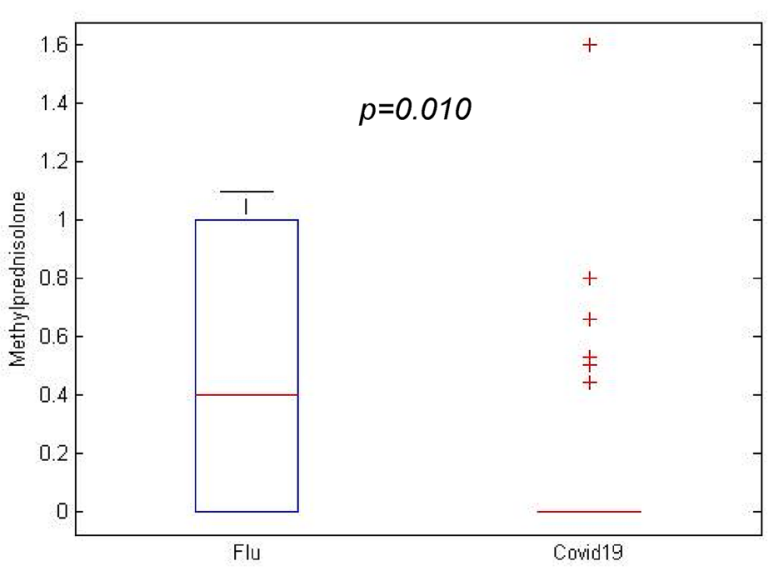

Fig. 2 Differences in SOFA score (a), White Blood Cells (b), Lymphocyte (c) absolute count and daily dosage of methylprednisolone (mg/kg/ die) (d) between patients with influenza (FLU) and coronavirus disease-19 (COVID-19). SOFA Sequential Organ Failure Assessment

[12010 (9820-12,700) vs 7030 (4927.5-9510) cells/mmc, $p=0.015]$; however, lymphocytes absolute count was significantly lower in FLU patients [395.5 (316-541) vs 770.0 (465-1165) cells/mmc, $p=0.005$ ] (Fig. 2b, c).
Corticosteroid use did not differ between the two groups (26.3\% vs 24\%, $p=0.9$ ), however, the dosage of corticosteroids (methylprednisolone, $\mathrm{mg} / \mathrm{kg} / \mathrm{die}$ ) was higher in FLU patients $(p=0.010)$ (Fig. 2, Panel D). Patients with 
COVID-19 received broad-spectrum antibiotics more frequently than patients with FLU $(92.7 \%$ vs $63.1 \%$, $p=0.0048$ ); in detail, teicoplanin and piperacillin/tazobactam were commonly used in COVID-19 critically ill patients ( $81.8 \%$ vs $0 \%$ and $67.2 \%$ vs $17 \%, p<0.0001$ and $p=0.003$, respectively) due to a predefined protocol [31-33]. Patients with COVID-19 and FLU had the same length of hospitalization in the ICU [21 (12-37) vs 23 (17.5-36.5) days, $p=0.672$, respectively].

\section{Comparison of clinical outcomes}

Overall, 30-day mortality did not differ between the two groups $(63.1 \%$ vs $69 \%$ for FLU and COVID-19, respectively, $p=0.77$ ) (Fig. 3), as well as the occurrence of bacterial pulmonary superinfections, which, however, tended to be more frequent in FLU $(57.8 \%$ vs $36 \%, p=0.11)$. With regard to the isolates causing respiratory superinfections, Acinetobacter baumannii was more frequently observed in FLU patients, whereas Pseudomonas aeruginosa was more frequent in COVID-19 and OXA-48 carbapenemase-producing Klebsiella pneumoniae was found only in COVID-19 subjects. The latter finding was confirmed by the rate of OXA-48 rectal colonization in COVID-19 patients, probably representing a small outbreak within the ICU, which was further limited with appropriate infection control measures [34]. The rate of bloodstream infections was similar, with 8 (42.1\%) and 23 (42\%) events in FLU and COVID-19 subjects, respectively $(p=0.589)$. Again, no difference among causative agents was found.

Documented thrombotic events were higher in patients with COVID-19 $(12 / 55,21.8 \%)$ compared to FLU group $(3 / 19,15.7 \%)$, in the absence of statistical significance $(p=0.521)$.

BAL GM was performed in 18 out of the 19 FLU patients. Conversely, in patients with COVID-19, BAL GM was performed in 39 patients (70.9\%), only on ICU admission during the first period of pandemic (March-May 2020) and on ICU admission, at day 7 and if the patient showed evidence of clinical disease progression thereafter (Fig. 1).

IPA was significantly associated with FLU with only two cases of CAPA detected over the study period $(6 / 19,31.5 \%$ vs $2 / 55,3.6 \%, p=0.0029)$. BAL GM was positive in $4 / 5$ (80\%) patients with IAPA, BAL culture detected Aspergillus fumigatus in one patients and serum GM, when performed, was negative. Autopsy proved IPA in one patient with FLU, with growth of Aspergillus fumigatus. In patients with COVID-19, BAL cultures were negative, whereas BAL GM was positive in two patients. According to the modified AspICU algorithm, FLU patients had one proven and
Fig. 3 Cumulative survival probability in patients with influenza (FLU) and coronavirus disease-19 (COVID-19)

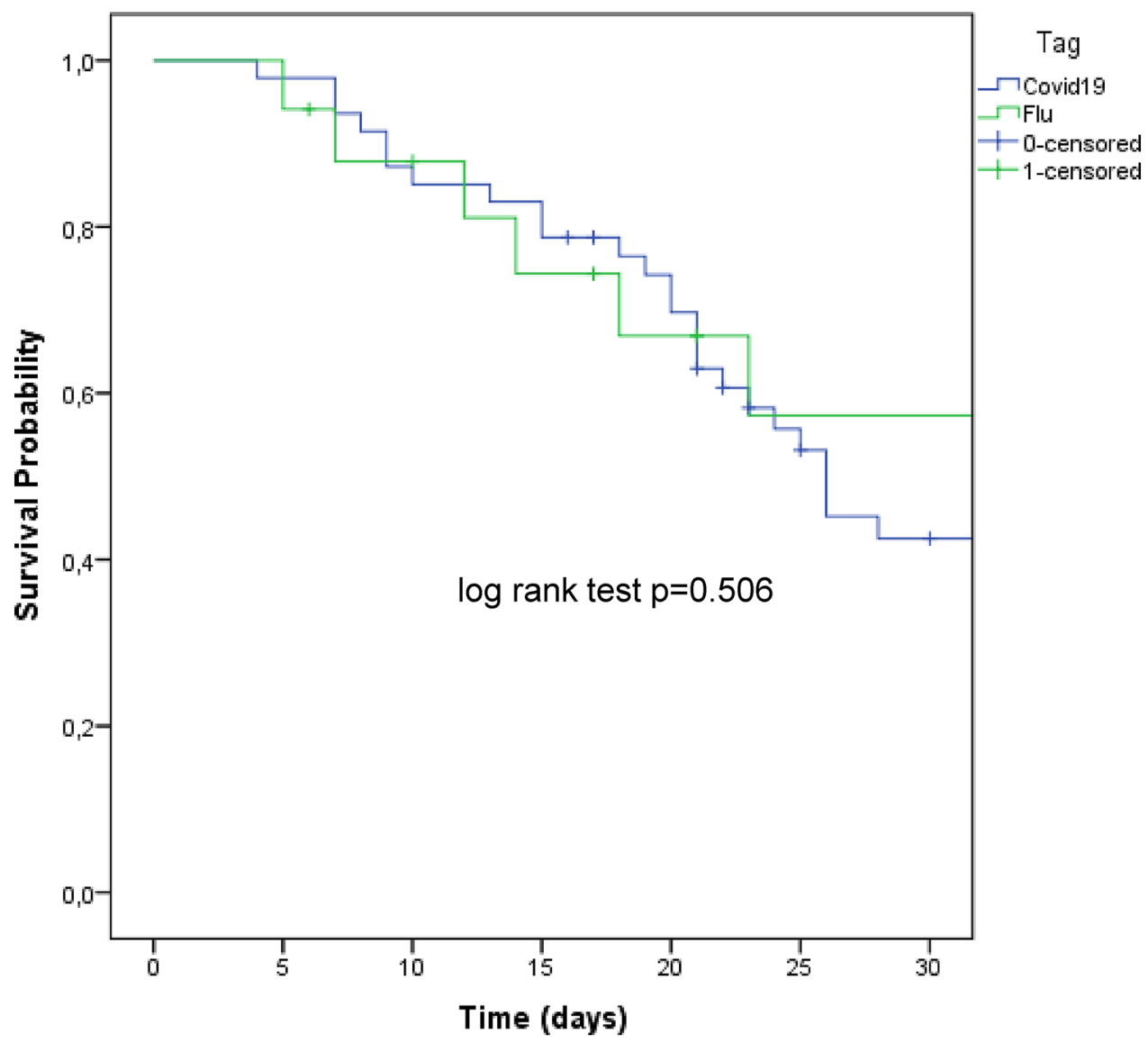


four putative IPA, whereas no patients with COVID-19 had proven or putative IPA (Table2).

At the multivariable analysis, male sex (OR 6.1, $p<0.002$ ), age $>65$ years (OR $2.4, p=0.024$ ) and lymphocyte count $>725$ cells/mmc at ICU admission (OR 5.1, $p=0.024)$ were significantly associated with COVID-19, whereas the presence of CKD and COPD were associated with FLU (OR 0.1 and OR 0.16, $p=0.020$ and $p<0.001$, respectively). Of note, IPA was significantly associated with FLU (OR 0.02, $p=0.011$ ) (Table 3).

Table 2 Characteristics of COVID-19 patients with IAPA $(n=6)$ and CAPA $(n=2)$

\begin{tabular}{|c|c|c|c|c|c|c|c|c|}
\hline Cases & Age, Sex & Comorbidities & Lymphocytes & $\begin{array}{l}\text { BAL } \\
\text { GM/Aspergillus } \\
\text { spp growth in } \\
\text { BAL culture }\end{array}$ & $\begin{array}{l}\text { Modified } \\
\text { AspICU }^{\mathrm{a}}\end{array}$ & $\begin{array}{l}\text { Radiological find- } \\
\text { ings }\end{array}$ & $\begin{array}{l}\text { Anti- } \\
\text { fungal } \\
\text { therapy }\end{array}$ & Outcome \\
\hline \multicolumn{9}{|l|}{$\begin{array}{l}\text { IAPA } \\
\text { (influenza type) }\end{array}$} \\
\hline $\begin{array}{l}\text { Case\#1 } \\
(\mathrm{H} 1 \mathrm{~N} 1)\end{array}$ & $58, \mathrm{M}$ & CAD & 304 & $1 /$ no growth & Putative & $\begin{array}{l}\text { X-ray (diffuse bilat- } \\
\text { eral interstitial } \\
\text { infiltrates) }\end{array}$ & ISA & Died \\
\hline Case\#2 (A) & $48, \mathrm{~F}$ & COPD & 320 & $3.6 /$ no growth & Putative & $\begin{array}{l}\text { CT (AIR with } \\
\text { bud in tree } \\
\text { lesions + ANGIO } \\
\text { with multiple } \\
\text { mycetomas) }\end{array}$ & VOR & Died \\
\hline $\begin{array}{l}\text { Case\#3 } \\
(\mathrm{H} 1 \mathrm{~N} 1)\end{array}$ & $71, \mathrm{M}$ & COPD, CKD & 300 & $3.2 /$ no growth & Putative & $\begin{array}{l}\text { CT (ANGIO with } \\
\text { nodules and } \\
\text { mixed alveolar } \\
\text { and GG lesions) }\end{array}$ & VOR & Died \\
\hline $\begin{array}{l}\text { Case\#4 } \\
(\text { H1N1) }\end{array}$ & $85, \mathrm{~F}$ & COPD & 274 & $\mathrm{NP}^{\mathrm{b}}$ /growth & Putative & $\begin{array}{l}\text { CT (ANGIO with } \\
\text { multiple myceto- } \\
\text { mas) }\end{array}$ & ISA & Died \\
\hline Case\#5 (A) & $66, \mathrm{M}$ & COPD & 210 & $>2.4^{\mathrm{c}} /$ no growth & Putative & $\begin{array}{l}\text { CT (ANGIO with } \\
\text { mycetomas and } \\
\text { mixed alveolar } \\
\text { and GG lesions) }\end{array}$ & ISA & Survived \\
\hline Case\#6 (B) & $59, \mathrm{M}$ & None & 270 & NP/NP & Proven* & $\begin{array}{l}\text { CT (diffuse bilat- } \\
\text { eral interstitial } \\
\text { infiltrates and } \\
\text { crazy paving) }\end{array}$ & CAS & Died \\
\hline \multicolumn{9}{|l|}{ CAPA } \\
\hline Case\#1 & $39, \mathrm{M}$ & Obesity & 1050 & $>2.3 /$ no growth & - & $\begin{array}{l}\text { CT (Multiple } \\
\text { bilateral GG and } \\
\text { crazy paving } \\
\text { lesions)** }\end{array}$ & No & Survived \\
\hline Case\#2 & $58, \mathrm{M}$ & None & 1150 & $>2.3 /$ no growth & - & $\begin{array}{l}\text { CT (Multiple } \\
\text { bilateral GG and } \\
\text { crazy paving } \\
\text { lesions)** }\end{array}$ & No & Survived \\
\hline
\end{tabular}

IAPA Influenza Associated Pulmonary Aspergillosis, CAPA COVID-19 Associated Pulmonary Aspergillosis, BAL bronchoalveolar lavage, SER serum, $C A D$ coronary artery disease, $C O P D$ chronic obstructive pulmonary disease, $C K D$ chronic kidney disease, $N P$ not performed, $C T$ computed tomography, GM galactomannan, AIR airway-invasive aspergillosis [41], ANGIO angio-invasive aspergillosis [50], GG ground glass, ISA isavuconazole, $V O R$ voriconazole, $C A S$ caspofungin.

${ }^{\text {a } M o d i f i e d ~ A s p I C U ~ w a s ~ d e f i n e d ~ i n ~ a c c o r d a n c e ~ t o ~[13] ~}$

bserum GM:0.5

${ }^{\mathrm{c}}$ BAL GM dropped to 0.9 under therapy

*diagnosis of aspergillosis was confirmed at autopsy with Aspergillus fumigatus growth, CAS was started empirically;

**: radiological examinations were consistent with COVID-19 pneumonia 
Table 3 Multivariable analysis of factors associated with COVID-19 $(\mathrm{OR}>1)$ or FLU $(\mathrm{OR}<1)$

\begin{tabular}{llcc}
\hline Parameter & OR & $95 \%$ CI & $p$ value \\
\hline Male sex & 6.1 & $1.9-18.9$ & 0.002 \\
Age $>$ 65 years & 2.4 & $1.1-6.6$ & 0.024 \\
Lymphocytes $>$ 725/ $\mu \mathrm{L}$ & 5.1 & $1.2-21.3$ & 0.024 \\
Corticosteroids & 1.3 & $0.4-4.6$ & 0.631 \\
Dosage of methylpredniso- & 0.3 & $0.01-1.1$ & 0.432 \\
$\quad$ lone (mg/kg/die) & & & \\
SOFA & 0.46 & $0.1-1.7$ & 0.25 \\
COPD & 0.16 & $0.05-0.5$ & $<0.001$ \\
CKD & 0.1 & $0.01-0.6$ & 0.020 \\
Pulmonary aspergillosis & 0.02 & $0.001-0.42$ & 0.011 \\
\hline
\end{tabular}

COVID-19 coronavirus disease-19, FLU influenza, SOFA sequential organ failure assessment, $C O P D$ chronic obstructive pulmonary disease, $C K D$ chronic kidney disease

\section{Discussion}

Symptoms of COVID-19 appear very similar to FLU, especially in the early phase of infection, and therefore, FLU represents an optimal comparator for COVID-19. To date, clinical features and outcomes in critically ill patients with FLU and COVID-19 are not widely described [35-38]. Therefore, in the present study, we contributed to the comparison between FLU and COVID-19 and we found that in critically ill patients requiring ICU admission male sex, age $>65$ and higher lymphocytes counts were associated with COVID-19, whereas CKD and COPD were related to FLU, respectively.

Male gender has been already linked to more severe symptoms, higher mortality rate and a more prolonged viral shedding than female in COVID-19 [39]. Our data suggest that gender per se may predispose males to COVID19 , possibly related to the effect of gender on viral receptor expression [40]. Elderly was another independent factor associated more with COVID-19 than with FLU, confirming the literature data available so far, which recognize age as a risk factor for severe COVID-19 and mortality [40]. In contrast, elder subjects were more frequently vaccinated for FLU, with consequent possible lower predisposition to this infection.

COPD was associated more with FLU than with COVID19 , suggesting that the presence of lung damage from a preexisting condition might be per se necessary for ICU admission in the case of FLU but not in the case of COVID-19.

As far as the clinically relevant outcomes are concerned, no differences in mortality rate, bacterial superinfections and thrombotic events were found. Conversely, IPA was significantly associated with FLU. During the study period, only two cases of CAPA were detected, with non-specific radiological findings and, most important, with recovery even in the absence of antifungal therapy (Table 2). In contrast, patients with IAPA presented with typical air and/or angioinvasive patterns on radiological examination [41] in all but one patients and had poor outcomes (5/6 death, 83.3\%) despite antifungal therapy.

Of note, FLU subjects had significantly lower lymphocytes counts than COVID-19 ones (Table 2), possibly explaining the observed higher rate of IAPA than CAPA. As a matter of fact, while lymphocytopenia has been identified as a potential risk factor for Aspergillus spp pulmonary superinfection following severe FLU [30], the exact role of lymphocyte count in the pathogenesis of IPA following COVID-19 is still unknown and, in our opinion, deserves additional investigations.

Although IAPA is a well-recognized clinical entity, data regarding the association between IPA and COVID-19 are still conflicting [1-27, 42-46]. Overall, we found a lower prevalence of CAPA (3.6\%) than that reported so far, which ranged from 3.3 to $33.3 \%$ of ICU subjects with COVID-19, with a recent review of the literature reporting a total of 93 ICU patients who developed IPA after a mean ICU stay of 7 days [27]. Despite this variability, the results of autopsy studies are worth of mention since IPA was a frequent cause of death in COVID-19 patients who eventually developed ARDS [47]. On the other hand, Razazi et al. found a very low prevalence of IPA (diagnosed according to the AspICU algorithm) in COVID-19 patients with ARDS (2/90, 2\%) compared to 12/82 (14.6\%) in patients with ARDS caused by other viruses [48].

The observed differences in CAPA prevalence might be explained by the difficulty in recognizing this emerging condition, the possible absence of specific radiological patterns and the variability of diagnostic definitions [46]. Last, but not least, it is well known that building-work activities inside or near the hospital allow dust contamination and fungal spores' dissemination and, therefore, might explain differences in IPA prevalence among studies [49]. However, it should be acknowledged that IPA following COVID-19 has been associated to mortality rates higher than 50\% [17]. As a consequence, physicians should anyway consider IPA as a possible cause of pneumonia progression in COVID-19 patients and include this potentially fatal complication in the differential diagnosis even in the absence of typical radiological findings.

In the present study, bacterial superinfections were a common finding in both FLU and COVID-19, with a prevalence of Gram-negative microorganisms. These findings are in line with the recent literature date, which showed that bacterial superinfections might complicate up to half of COVID-19 patients admitted to ICU, with a high case fatality rate [4]. However, similarly to what observed for IPA, rates of bacterial superinfections varied widely among the published studies [5, 6]. Therefore, we could speculate that the real prevalence of bacterial and fungal superinfections 
in COVID-19 critically ill patients is still unknown and may be influenced by the different local epidemiology as well as by the different therapeutic approaches.

Both FLU and COVID-19 are associated with severe cardiovascular and cardiorespiratory complications, mainly due to the occurrence of thrombotic events [7, 9, 28, 50]. Although in the absence of statistical significance, we found a higher occurrence of thrombotic events in patients with COVID-19 than with FLU, confirming that coagulopathy represents a crucial aspect of this condition, possibly driven by the activation of NADPH oxidase and by an excessive harmful pro-inflammatory response [28].

The present investigation has several limitations, which should be taken into consideration. First, the retrospective and single-center nature of the study with the consequent low number of included patients. Then, the search for IPA changed during the study period, a fact that might have possibly underestimate the real prevalence of this condition, which was, however, very low even after the implementation of a more aggressive diagnostic approach. Third, patients with FLU and COVID-19 belonged to different periods since during the 2020 our hospital was exclusively dedicated to COVID-19 patients.

\section{Conclusion}

In critically ill patients, male sex, age $>65$ years and lymphocytes absolute count $>725$ cells $/ \mathrm{mmc}$ are related to COVID-19, whereas COPD and CKD are more typical of FLU. In our population, FLU was associated with a significantly higher risk of IPA than COVID-19.

Acknowledgements This research did not receive any specific grant from funding agencies in the public, commercial, or not-for-profit sectors.

Funding Open access funding provided by Università degli Studi di Roma La Sapienza within the CRUI-CARE Agreement.

Data availability statement Data are available upon request from corresponding author.

\section{Declarations}

Ethical approval The study was conducted according to the guidelines of the Declaration of Helsinki and approved by the local Institutional Review Board.

Open Access This article is licensed under a Creative Commons Attribution 4.0 International License, which permits use, sharing, adaptation, distribution and reproduction in any medium or format, as long as you give appropriate credit to the original author(s) and the source, provide a link to the Creative Commons licence, and indicate if changes were made. The images or other third party material in this article are included in the article's Creative Commons licence, unless indicated otherwise in a credit line to the material. If material is not included in the article's Creative Commons licence and your intended use is not permitted by statutory regulation or exceeds the permitted use, you will need to obtain permission directly from the copyright holder. To view a copy of this licence, visit http://creativecommons.org/licenses/by/4.0/.

\section{References}

1. World Health Organization. (2020) WHO Director-General's opening remarks at the media briefing on COVID-19.cited 2020 Jul 26. https://www.who.int/dg/speeches/detail/who-directorgeneral-s-opening-remarks-at-the-media-briefing-on-covid- 19 . Accessed 11 march 2020

2. Johns Hopkins University. (2020) COVID-19 Map. Johns Hopkins Coronavirus Resource Center. 260. https://coronavirus.jhu. edu/map.html. Accessed 9 Oct 2020

3. Sue Huang Q, Wood T, Jelley L, Jennings T, Jefferies S, Daniells K, et al. Impact of the COVID-19 nonpharmaceutical interventions on influenza and other respiratory viral infections in New Zealand. Nat Commun. 2021;12(1):1001. https://doi.org/ 10.1038/s41467-021-21157-9.

4. Bassetti M, Kollef MH, Timsit JF. Bacterial and fungal superinfections in critically ill patients with COVID-19. Intensive Care Med. 2020;46(11):2071-4. https://doi.org/10.1007/ s00134-020-06219-8.

5. Chong WH, Saha BK, Ramani A, Chopra A. State-of-the-art review of secondary pulmonary infections in patients with COVID-19 pneumonia. Infection. 2021. https://doi.org/10.1007/ s15010-021-01602-z.

6. Garcia-Vidal C, Sanjuan G, Moreno-García E, Puerta-Alcalde $\mathrm{P}$, Garcia-Pouton $\mathrm{N}$, Chumbita $\mathrm{M}$, et al. Incidence of coinfections and superinfections in hospitalized patients with COVID-19: a retrospective cohort study. Clin Microbiol Infect. 2021;27(1):83-8. https://doi.org/10.1016/j.cmi.2020.07.041.

7. Dolby HW, Potey P, Wilder-Smith AB, Clohisey S, Millar JE, Kenneth Baillie J, et al. Histological evidence of pulmonary microthrombosis and vasculitis in life-threatening respiratory virus diseases. Open Forum Infect Dis. 2020;8(2):ofaa640. https://doi.org/10.1093/ofid/ofaa640 (eCollection 2021 Feb).

8. Ackermann M, Verleden SE, Kuehnel M, Haverich A, Welte T, Laenger F, et al. Pulmonary vascular endothelialitis, thrombosis, and angiogenesis in Covid-19. N Engl J Med. 2020;383(2):120 8. https://doi.org/10.1056/NEJMoa2015432 (Epub 2020 May 21).

9. Violi F, Giancarlo C, Roberto C, Francesco A, Gabriella D, Alessandra $\mathrm{O}$, et al. Hypoalbuminemia, coagulopathy, and vascular disease in COVID-19. Circ Res. 2020;127(3):400-1.

10. Oliva A, Siccardi G, Migliarini A, Cancelli F, Carnevalini M, D'Andria M, Attilia I, Danese VC, Cecchetti V, Romiti R, Ceccarelli G, Mastroianni CM, Palange P, Venditti M. Co-infection of SARS-CoV-2 with Chlamydia or Mycoplasma pneumoniae: a case series and review of the literature. Infection. 2020;28:1-7. https://doi.org/10.1007/s15010-020-01483-8.

11. Robinson KM, Ramanan K, Tobin JM, Nickolich KL, Pilewski MJ, Kallewaard NL, et al. Survival during influenza-associated bacterial superinfection improves following viral- and bacterialspecific monoclonal antibody treatment. JCI Insight. 2019. https:// doi.org/10.1172/jci.insight.125554.

12. Moretti M, Van Laethem J, Minini A, Pierard D, Manu LNG, Malbrainf. Ventilator-associated bacterial pneumonia in coronavirus 2019 disease, a retrospective monocentric cohort study. J Infect Chemother. 2021. https://doi.org/10.1016/j.jiac.2021.01.011. 
13. Schauwvlieghe AFAD, Rijnders BJA, Philips N, Verwijs R, Vanderbeke L, Van Tienen C, et al. Invasive aspergillosis in patients admitted to the intensive care unit with severe influenza: a retrospective cohort study. Lancet Respir Med. 2018;6(10):782-92. https://doi.org/10.1016/S2213-2600(18)30274-1.

14. Verweij PE, Rijnders BJA, Bruggemann RJM, et al. Review of influenza-associated pulmonary aspergillosis in ICU patients and proposal for a case definition: an expert opinion. Intensive Care Med. 2020;46(8):1524-35. https://doi.org/10.1007/ s00134-020-06091-6.

15. Koehler P, Bassetti M, Kochanek M, Shimabukuro-Vornhagen A, Cornely OA. Intensive care management of influenzaassociated pulmonary aspergillosis. Clin Microbiol Infect. 2019;25(12):1501-9. https://doi.org/10.1016/j.cmi.2019.04.031.

16. Verweij PE, Gangneux J-P, Bassetti M, et al. Diagnosing COVID-19-associated pulmonary aspergillosis. Lancet Microbe. 2020;1:e53-5. https://doi.org/10.1016/S2666-5247(20)30027-6.

17. Bartoletti M, Pascale R, Cricca M, et al. Epidemiology of invasive pulmonary aspergillosis among COVID-19 intubated patients: a prospective study. Clin Infect Dis. 2020. https://doi. org/10.1093/cid/ciaa1065.

18. Alanio A, Delliere S, Fodil S, Bretagne S, Megarbane B. Prevalence of putative invasive pulmonary aspergillosis in critically ill patients with COVID-19. Lancet Respir Med. 2020;8(6):e489. https://doi.org/10.1016/S2213-2600(20)30237-X.

19. Falces-Romero I, Ruiz-Bastián M, Díaz-Pollán B, Maseda E, García-Rodríguez J, Group SA-C-W. Isolation of Aspergillus spp. in respiratory samples of patients with COVID-19 in a Spanish Tertiary Care Hospital. Mycoses. 2020;63(11):1144-8. https://doi.org/10.1111/myc.13155.

20. Rutsaert L, Steinfort N, Van Hunsel T, et al. COVID-19-associated invasive pulmonary aspergillosis. Ann Intensive Care. 2020;10(1):71. https://doi.org/10.1186/s13613-020-00686-4.

21. van Arkel ALE, Rijpstra TA, Belderbos HNA, van Wijngaarden P, Verweij PE, Bentvelsen RG. COVID-19-associated pulmonary aspergillosis. Am J Respir Crit Care Med. 2020;202(1):132-5. https://doi.org/10.1164/rccm. 202004-1038LE.

22. Lescure FX, Bouadma L, Nguyen D, et al. Clinical and virological data of the first cases of COVID-19 in Europe: a case series. Lancet Infect Dis. 2020;20(6):697-706. https://doi.org/10.1016/ S1473-3099(20)30200-0.

23. Koehler P, Cornely OA, Bottiger BW, et al. COVID-19 associated pulmonary aspergillosis. Mycoses. 2020;63(6):528-34. https:// doi.org/10.1111/myc.13096.

24. Lamoth F, Glampedakis E, Boillat-Blanco N, Oddo M, Pagani JL. Incidence of invasive pulmonary aspergillosis among critically ill COVID-19 patients. Clin Microbiol Infect. 2020. https://doi.org/ 10.1016/j.cmi.2020.07.010.

25. Lahmer T, Rasch S, Spinner C, Geisler F, Schmid RM, Huber W. Invasive pulmonary aspergillosis in severe coronavirus disease 2019 pneumonia. Clin Microbiol Infect. 2020;26(10):1428-9. https://doi.org/10.1016/j.cmi.2020.05.032.

26. Antinori S, Rech R, Galimberti L, et al. Invasive pulmonary aspergillosis complicating SARS-CoV-2 pneumonia: a diagnostic challenge. Travel Med Infect Dis. 2020. https://doi.org/10.1016/j. tmaid.2020.101752.

27. Machado M, Valerio M, Álvarez-Uría A, Olmedo M, Veintimilla C, Padilla B, et al. Invasive pulmonary aspergillosis in the COVID-19 era: an expected new entity. Mycoses. 2021;64(2):132-43. https://doi.org/10.1111/myc.13213.

28. Violi F, Oliva A, Cangemi R, Ceccarelli G, Pignatelli P, Carnevale R, Cammisotto V, Lichtner M, Alessandri F, De Angelis M, Miele MC, D'Ettorre G, Ruberto F, Venditti M, Pugliese F, Mastroianni CM. Nox2 activation in Covid-19. Redox Biol. 2020. https://doi. org/10.1016/j.redox.2020.101655.
29. World Health Organization. (2020) Clinical management of COVID-19: interim guidance, cited 1 Aug 2020. https://apps. who.int/iris/handle/10665/332196. Accessed 27 May 2020

30. Bellelli V, d'Ettorre G, Celani L, Borrazzo C, Ceccarelli G, Venditti M. Clinical significance of lymphocytopenia in patients hospitalized with pneumonia caused by influenza virus. Crit Care. 2019;23(1):330. https://doi.org/10.1186/s13054-019-2608-1.

31. Ceccarelli G, Alessandri F, d'Ettorre G, Borrazzo C, Spagnolello $\mathrm{O}$, Oliva A, et al. Is teicoplanin a complementary treatment option for COVID-19? The question remains. Int J Antimicrob Agents. 2020;56(2):106029-106029.

32. Ceccarelli G, Alessandri F, Oliva A, et al. Superinfections in patients treated with Teicoplanin as anti-SARSCoV2 agent. Eur J Clin Invest. 2020. https://doi.org/10.1111/eci.13418.

33. Ceccarelli G, Alessandri F, Oliva A, Borrazzo C, Dell'Isola S, Ialungo AM, et al. The role of teicoplanin in the treatment of SARS-CoV-2 infection: A retrospective study in critically ill COVID-19 patients (Tei-COVID study). J Med Virol. 2021. https://doi.org/10.1002/jmv.26925.

34. Arcari G, Raponi G, Sacco F, Bibbolino G, Lella FMD, Alessandri F, et al. Klebsiella pneumoniae infections in COVID-19 patients: a 2-month retrospective analysis in an Italian hospital. Int J Antimicrob Agents. 2021;57(1):106245. https://doi.org/10. 1016/j.ijantimicag.2020.106245 (Epub 2020 Nov 27).

35. Brehm TT, van der Meirschen M, Hennigs A, Roedl K, Jarczak $\mathrm{D}$, Wichmann D, et al. Comparison of clinical characteristics and disease outcome of COVID-19 and seasonal influenza. Sci Rep. 2021;11(1):5803. https://doi.org/10.1038/s41598-021-85081-0.

36. Faury H, Courboulès C, Payen M, Jary A, Hausfater P, Luyt CharlesEdouard, et al. Medical features of COVID-19 and influenza infection: a comparative study in Paris. France J Infect. 2021;82(2):e36-9. https://doi.org/10.1016/j.jinf.2020.08.017 (Epub 2020 Aug 14).

37. Ludwig M, Jacob J, Basedow F, Andersohn F, Walker J. Clinical outcomes and characteristics of patients hospitalized for Influenza or COVID-19 in Germany. Int J Infect Dis. 2021;103:316-22. https://doi.org/10.1016/j.ijid.2020.11.204 (Epub 2020 Dec 31).

38. Curtolo A, Oliva A, Volpicelli L, Ceccarelli G, D'Ettorre G, Borrazzo $\mathrm{C}$, Mastroianni $\mathrm{CM}$, Venditti $\mathrm{M}$. Monocyte absolute count as a preliminary tool to distinguish between SARS-CoV-2 and influenza $\mathrm{A} / \mathrm{B}$ infections in patients requiring hospitalization. Infez Med. 2020;28(4):534-8.

39. Cogliati Dezza F, Oliva A, Cancelli F, Savelloni G, Valeri S, Mauro V, et al. Determinants of prolonged viral RNA shedding in hospitalized patients with SARS-CoV-2 infection. Diagn Microbiol Infect Dis. 2021. https://doi.org/10.1016/j.diagmicrobio.2021. 115347.

40. Zhou F, Yu T, Du R, Fan G, Liu Y, Liu Z, et al. Clinical course and risk factors for mortality of adult inpatients with COVID19 in Wuhan, China: a retrospective cohort study. The Lancet. 2020;395(10229):1054-62.

41. Muñoz P, Vena A, Cerón I, Valerio M, Palomo J, Guinea J, et al. Invasive pulmonary aspergillosis in heart transplant recipients: two radiologic patterns with a different prognosis. J Heart Lung Transplant. 2014;33(10):1034-40. https://doi.org/10.1016/j. healun.2014.05.003.

42. Permpalung N, Chiang T-Y, Massie AB, Zhang SX, Avery RK, Nematollahi S, et al. COVID-19 associated pulmonary aspergillosis in mechanically ventilated patients. Clin Infect Dis. 2021. https://doi.org/10.1093/cid/ciab223 (Online ahead of print).

43. Lahmer T, Kriescher S, Herner A, Rothe K, Spinner CD, Schneider $\mathbf{J}$, et al. Invasive pulmonary aspergillosis in critically ill patients with severe COVID-19 pneumonia: Results from the prospective AspCOVID-19 study. PLoS ONE. 2021;16(3):e0238825. https://doi.org/10.1371/journal.pone.0238825 (eCollection 2021). 
44. Dupont D, Menotti J, Turc J, Miossec C, Wallet F, Richard J-C, et al. Pulmonary aspergillosis in critically ill patients with Coronavirus Disease 2019 (COVID-19). Med Mycol. 2021;59(1):110-4. https://doi.org/10.1093/mmy/myaa078.

45. Fekkar A, Lampros A, Mayaux J, Poignon C, Demeret S, Constantin J-M, et al. Occurrence of invasive pulmonary fungal infections in patients with severe COVID-19 admitted to the ICU. Am J Respir Crit Care Med. 2021;203(3):307-17. https://doi.org/10. 1164/rccm.202009-3400OC.

46. Lamoth F, Lewis RE, Walsh TJ, Kontoyiannis DP. Navigating the uncertainties of COVID-19 associated aspergillosis (CAPA): A comparison with influenza associated aspergillosis (IAPA). J Infect Dis. 2021. https://doi.org/10.1093/infdis/jiab163.

47. Evert K, Dienemann T, Brochhausen C, Lunz D, Lubnow M, Ritzka M, et al. Autopsy findings after long-term treatment of COVID-19 patients with microbiological correlation. Virchows Arch. 2021. https://doi.org/10.1007/s00428-020-03014-0 (Online ahead of print).
48. Razazi K, Arrestier R, Haudebourg AF, Benelli B, Carteaux G, Decousser J-W, et al. Risks of ventilator-associated pneumonia and invasive pulmonary aspergillosis in patients with viral acute respiratory distress syndrome related or not to Coronavirus 19 disease. Crit Care. 2020;24(1):699. https://doi.org/10.1186/ s13054-020-03417-0.

49. La Milia DI, Vincenti S, Fiori B, Pattavina F, Torelli R, Barbara A, et al. Monitoring of particle environmental pollution and fungal isolations during hospital building-work activities in a hematology ward. Mediterr J Hematol Infect Dis. 2019;11(1):e2019062. https://doi.org/10.4084/MJHID.2019.062 (eCollection 2019).

50. Violi F, Cangemi R, Romiti GF, Ceccarelli G, Oliva A, Alessandri F, et al. Is albumin predictor of mortality in COVID-19? Antioxid Redox Signal. 2020. https://doi.org/10.1089/ars.2020.8142. 